\title{
FRAGMENTAÇÃO FLORESTAL: DEFINIÇÃO E IMPACTOS SEGUNDO A LITERATURA CIENTÍFICA
}

\author{
Caroline Tavares Firmino ${ }^{1}$ \\ Gizely Azevedo Costa ${ }^{2}$ \\ Jefferson Luiz Ferrari ${ }^{3}$ \\ Daiani Bernardo Pirovani ${ }^{4}$
}

Resumo: Em virtude da maior demanda de áreas para as atividades econômicas, muito da riqueza natural do meio ambiente vem sendo perdida através de desmatamentos e queimadas que geram a fragmentação florestal, um processo cujos efeitos não são conhecidos em toda sua amplitude. Objetivou-se avaliar o conceito de fragmento florestal perante o meio acadêmico e cientifico, bem como discutir os principais impactos decorrentes da fragmentação florestal. A metodologia adota para a realização da pesquisa se baseou na leitura e analise de bibliografias especificas sobre o tema em questão. Observou-se que, segundo a literatura, um fragmento florestal compreende uma unidade de floresta natural contínua, interrompida por barreiras naturais ou antrópicas, tendo como efeitos principais a perda de biodiversidade e o efeito de borda. Assim, torna-se fundamental o incentivo a ações de preservação dos fragmentos florestais, buscando, se possível, a conexão dos remanescentes florestais.

Palavras-chave: Fragmentação florestal; Perda de biodiversidade; Ecologia da paisagem.

\footnotetext{
${ }^{1}$ Bacharelado em Ciências Biológicas / Instituto Federal do Espírito Santo - Campus de Alegre, Alegre, ES, Brasil. E-mail: tavares.carolini@gmail.com.

2 Bacharelado em Ciências Biológicas / Instituto Federal do Espírito Santo - Campus de Alegre, Alegre, ES, Brasil. E-mail: gizelyac.11@hotmail.com.

3 Professor Doutor / Instituto Federal do Espírito Santo - Campus de Ibatiba, Ibatiba, ES, Brasil. E-mail: ferrarijluiz@gmail.com.

4 Professora Doutora / Instituto Federal do Espírito Santo - Campus de Ibatiba, Ibatiba, ES, Brasil. E-mail: daiani.pirovani@ifes.edu.br.
} 